\title{
Ethical Principles as a Basis for Disciplinary Responsibility
}

\section{Søren Birkeland*}

Department of Psychology, University of Southern Denmark, Denmark

*Corresponding author: Søren Birkeland, Department of Psychology, University of Southern Denmark, Denmark, Tel: +45 6550 2740; E-mail: sbirkeland@health.sdu.dk Rec date: Apr 18, 2014, Acc date: Jul 18, 2014, Pub date: Aug 26, 2014

Copyright: ( 2014 Birkeland S. This is an open-access article distributed under the terms of the Creative Commons Attribution License, which permits unrestricted use, distribution, and reproduction in any medium, provided the original author and source are credited.

\section{Commentary}

The assessment of professional duties and disciplinary responsibility in health care delivery may sometimes be difficult and often draw particular focus to evidence-based treatment strategies and adherence to various more or less 'operationalized' guidelines. Needless to say, direct reference to recommendations etc. occasionally is not sufficient to establish the scope of disciplinary responsibility while there is a desire to refer to some formal 'source of law'.

In Denmark, assessment of disciplinary (non-monetary) responsibility has been traditionally based upon the legal standards stated in formal authorization legislation. Currently, the Danish Act on Authorization of Health Professionals (877 dated 04/08/2011) Para 17 concerning Health Professionals' Duties etc. claims that "In the exercise of health care, an authorized health professional is required to behave carefully and conscientiously". For psychologists the duty is similarly expressed in Act on Psychologists (229 dated 08/03/2012), Para 12.

Whilst, for all authorized health care professionals, a specialized Disciplinary (Patient Complaints) Board considers cases concerning health professionals' diligence (and compliance with the aforementioned duty, Para 17), e.g. psychologists may be also brought before a specific Ethical Board which considers complaint cases beyond the health care system too. Based upon a set of Ethical Principles for Nordic Psychologists, a criticism can be issued (Vedtægter for Etiknævnet, Dansk Psykologforening, 2012-2014; compare the Danish Medical Association's Ethical Board and Code of
Conduct). Contrary to the vaguely defined formal law claim for 'careful and conscientious' conduct, these Ethical Principles specifically enumerates a number of requirements (e.g. demand for "consciousness about (the psychologist's) professional and personal stronger and weaker points, so that he/she can judge realistically with what degree of competence he/she can take on assignments. The psychologist takes on only those assignments, offers only those services and uses only those methods for which he/she is qualified through education, training and experience" as well as need to respect patient autonomy and integrity, obtaining informed consent etc).

Ethical principles may be present in several contexts and for various groups of health care professionals (compare, e.g., Madrid Declaration on Ethical Standards for Psychiatric Practice, 1996: "...Ethical practice is based on the psychiatrist's individual sense of responsibility to the patient and judgment in determining what is correct and appropriate conduct. ..").What, from this point of view, makes the ethical principles of particular interest is that, parallel to the 'objective' requirements for conformity with diverse standards, guidelines, and treatment recommendations, they may remind about the disciplinary responsibility's 'subjective constituent'. The latter implies that the elements of caregiver's 'rationale' and 'devotedness to duty' etc. are taken into consideration as well (cf. criminal law and procedure). By way of conclusion ethical principles may point to requirements that must be complied with judicially, but also stress the two-sided perspective that must be expected from health care users, the society, and among health care persons. 